\title{
THE INHERITANCE OF SEX-LIMITED BILATERAL ASYMMETRY IN BRUCHUS ${ }^{1}$
}

\author{
J. K. BREITENBECHER \\ Marine Biological Laboratory, Woods Hole, Massachusetts
}

Received January 28, 1925

TABLE OF CONTENTS

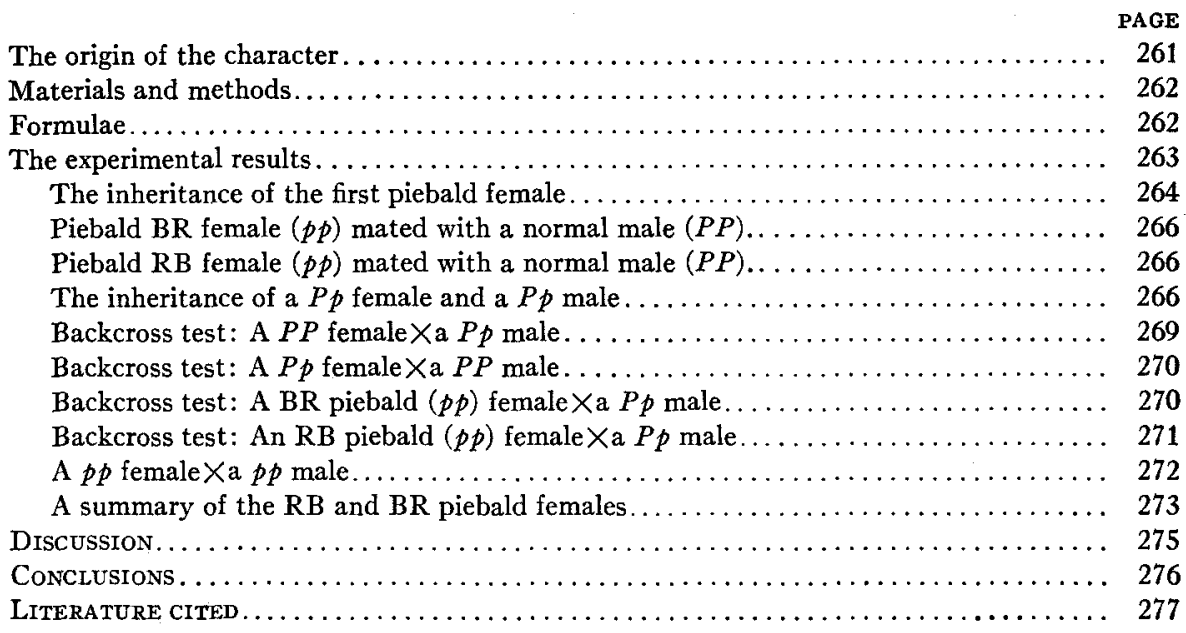

THE ORIGIN OF THE CHARACTER

The wild-type female, described in detail in previous publications, (BREITENBECHER 1921, 1922, 1923) has two black spots bilaterally located on each elytrum, while the wild male has no spots but transmits the genes (ss) for black spots. On October 23, 1922, there appeared in my cultures of Bruchus quadrimaculatus Fabr. an abnormal female with two red spots on her right elytrum instead of black spots, which are normally found on both elytra of the wild-type female. This unilateral insect originated from a homozygous culture (RRss) pure for red elytra and black spots. In cultures of this unilateral mutation, the abnormality, red spots on the right elytrum, and black spots on the left, did not breed true for this asymmetrical trait, but many females were found with the left elytrum

${ }^{1}$ The major portion of this experiment was conducted at the UNIVERSITY OF OKLAHoMa. It was completed at Woods Hole, Massachusetts, where the superior advantages of the MarINE Brological Laboratory were enjoyed through the kindness of Doctor Frank R. LiLlie. 
black spotted and the right elytrum red spotted, while many manifested the original type of spotting. The males, however, in the homozygous mutant cultures, for either type of female, were always non-spotted. The size of the spots varied from four minute patches to quite large ones. For these reasons, "piebald" seemed the most appropriate name for this mutation.

\section{MATERIALS AND METHODS}

The problem here is concerned only with elytra color and its spotting; hence, for each of the types described, only such traits will be discussed. The wild-type females had tan elytra with black spots, as previously shown (BREITENBECHER 1921, 1923). The piebald females were crossed with males of another (RRSS) type in order that the unilateral piebald black spot might be more distinctly visible on a red background. Two types of piebald females were discovered: One (RB) had red spots only on her left elytrum with black spots on her right elytrum; while the other (BR) had black spots on the left elytrum with red spots on the right elytrum. All piebald males, for both kinds of females. appeared alike, having somatically tan non-spotted elytra. Single pair matings were used throughout this test. Virgin females were obtained by removing them with a knife from the cowpeas a few hours before they emerged. The cowpeas were sterilized in Mason jars kept at a temperature of $50^{\circ} \mathrm{C}$ for one hour. Each pair was placed in a two-ounce bottle, filled with these cowpeas, and plugged with cotton. Humidity was provided by placing several cultures in glass battery jars filled with a layer of water. Each container was covered with a glass plate and sealed with vaseline. Each jar with its insects was kept in a constant-temperature oven at $40^{\circ} \mathrm{C}$. A generation would appear in about three weeks.

\section{FORMULAE}

The formulae used take into account both the sex-limited traits involved as well as both types of piebald females. The genes, $p p, \bar{p}_{-}$stand for the homozygous piebald recessive mutation.

The two types used are as follows:

(1) The normal type

(a) Females. Two bilateral red spots on each elytrum $(P P)$.

(b) Males. Non-spotted with tan elytra $(P P)$.

(2) The piebald type

(a) Females. Elytra spotting of two kinds $(p p)$.

RB elytra: left, red spots; right, black spots.

BR elytra: left, black spots; right, red spots.

(b) Males. All with non-spotted elytra $(p p)$. 
THE EXPERIMENTAL RESULTS

In the tests that follow, each individual carried some combination of the following factors: $P P, P p, p P$ and $p p$. The piebald cultures were crossed with stocks having $R R$ genes, homozygous for red elytra, and $S S$ factors, pure for red spots on the elytra, in order to contrast the black

TABLE 1

$P_{1}$ : A piebald female having red spots on her right elytrum and black spots on her left elytrum $\times a$ non-spotted male homozygous for red elytra color and red-spotted elytra.

$F_{1}$ : No piebald females, 23 females with normal bilateral red-spotted elyira, and 25 non-spotted males.

\begin{tabular}{|c|c|c|c|c|c|}
\hline \multirow{4}{*}{ PAIR NUMBER } & \multicolumn{4}{|c|}{ F, ELYTRAL SPOTTING } & \multirow{4}{*}{$\begin{array}{c}\text { Ratio } \\
\text { Red-spotted : piebalo }\end{array}$} \\
\hline & \multirow{3}{*}{ Red spots } & \multicolumn{2}{|c|}{ Females } & \multirow{3}{*}{$\begin{array}{l}\text { Males } \\
\text { No spots }\end{array}$} & \\
\hline & & \multicolumn{2}{|c|}{ Piebald } & & \\
\hline & & R B* & B R f & & \\
\hline 60.1 & 29 & 0 & 2 & 26 & $14.5: 1$ \\
\hline 60.2 & 37 & 3 & 1 & 33 & $9.2: 1$ \\
\hline 60.3 & 40 & 4 & 2 & 74 & $6.7: 1$ \\
\hline 60.4 & 0 & 0 & 0 & 25 & $0.0: 0$ \\
\hline 60.5 & 20 & 2 & 3 & 31 & $4.0: 1$ \\
\hline 60.6 & 34 & 1 & 5 & 44 & $5.7: 1$ \\
\hline 60.7 & 18 & 2 & 1 & 30 & $6.0: 1$ \\
\hline 60.8 & 16 & 2 & 2 & 25 & $4.0: 1$ \\
\hline 60.9 & 18 & 2 & 3 & 24 & $3.6: 1$ \\
\hline 60.10 & 46 & 5 & 4 & 40 & $5.1: 1$ \\
\hline 60.11 & 37 & 5 & 2 & 36 & $5.3: 1$ \\
\hline 60.12 & 51 & 1 & 3 & 37 & $12.7: 1$ \\
\hline 60.13 & 19 & 2 & 1 & 21 & $6.3: 1$ \\
\hline 60.14 & 14 & 0 & 0 & 17 & $14.0: 0$ \\
\hline 60.15 & 6 & 1 & 2 & 8 & $2.0: 1$ \\
\hline 60.16 & 29 & 1 & 3 & 30 & $7.2: 1$ \\
\hline 60.17 & 19 & 2 & $\mathbf{0}$ & 21 & $9.5: 1$ \\
\hline 60.18 & 9 & 1 & 2 & 11 & $3.0: 1$ \\
\hline Totals 18 pairs: & 442 & 34 & 36 & 533 & $6.3: 1$ \\
\hline
\end{tabular}

* $\mathrm{R} B$ indicates a female having red spots on the left elytrum and black spots on the right one.

$\dagger \mathrm{B} R$ indicates a female having black spots on the left elytrum and red spots on the right one.

piebald spotting on either elytrum with the background of a pure-red elytrum. The piebald mutation, having black spots on either elytrum was represented by the genes $p p$, while the normal type, having bilateral red elytra spots, transmitted the factors, $P P, P p$ and $p P$. As a result of such a cross, the actual genetic formulae for all of these traits were $R R S S P P$, $R R S S P p, R R S S p P$ and $R R S S p p$. Since every individual was homozygous for the RRSS genes, these unnecessary combinations have been omitted from all tables and from the discussion which follows. 
The inheritance of the first piebald female

The complete data for two generations of the descendants of the first piebald female crossed with a normal non-spotted male, are given in table 1. The piebald mother had two red spots on her right elytrum and

TABLE 2

$P_{1}$ : Piebald BR female $(p p) \times$ non-spotted male $(P P)$ pure for red spols.

$F_{1}:$ Red-spotted females $(P p)$ and non-spotted males $(P p)$.

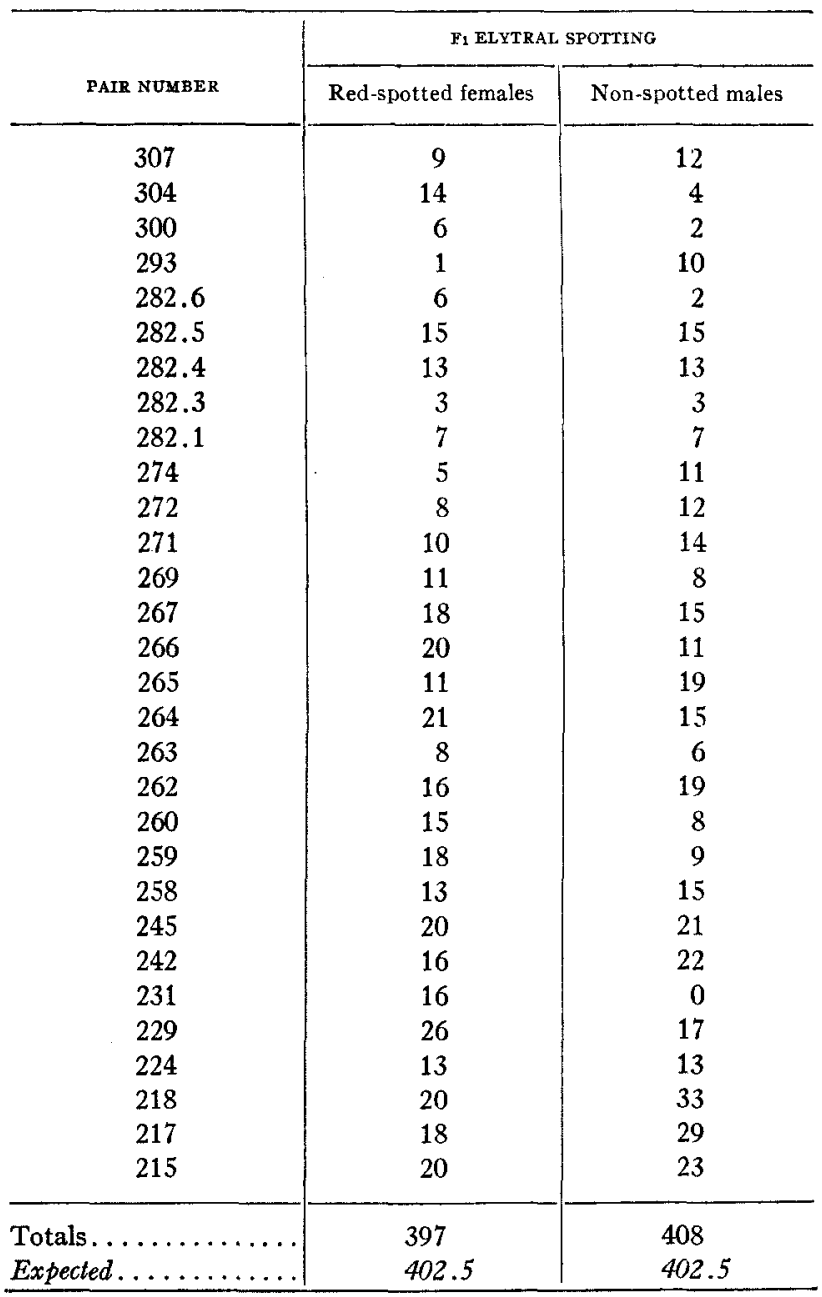

two black ones on her left elytrum. She was bred to a normal, tan-elytra, non-spotted male homozygous for red spots and tan elytra. Their $F_{1}$ offspring consisted of 23 females with normal, bilateral red-spotted elytra, 
no piebald females, and 25 non-spotted males. This test indicated that piebald was a recessive. Eighteen of these $F_{1}$ pairs were mated singly. The progeny of the above-mentioned pairs totaled 442 bilateral red-

TABLE 3

The same tests as enumerated in table 2.

$P_{1}$ : Piebald, $B R$ female $(p p) \times$ non-spotted male $(P P)$ pure jor red spots.

$F_{1}$ : Red-spotted females $(P p)$ and non-spotted males $(P p)$.

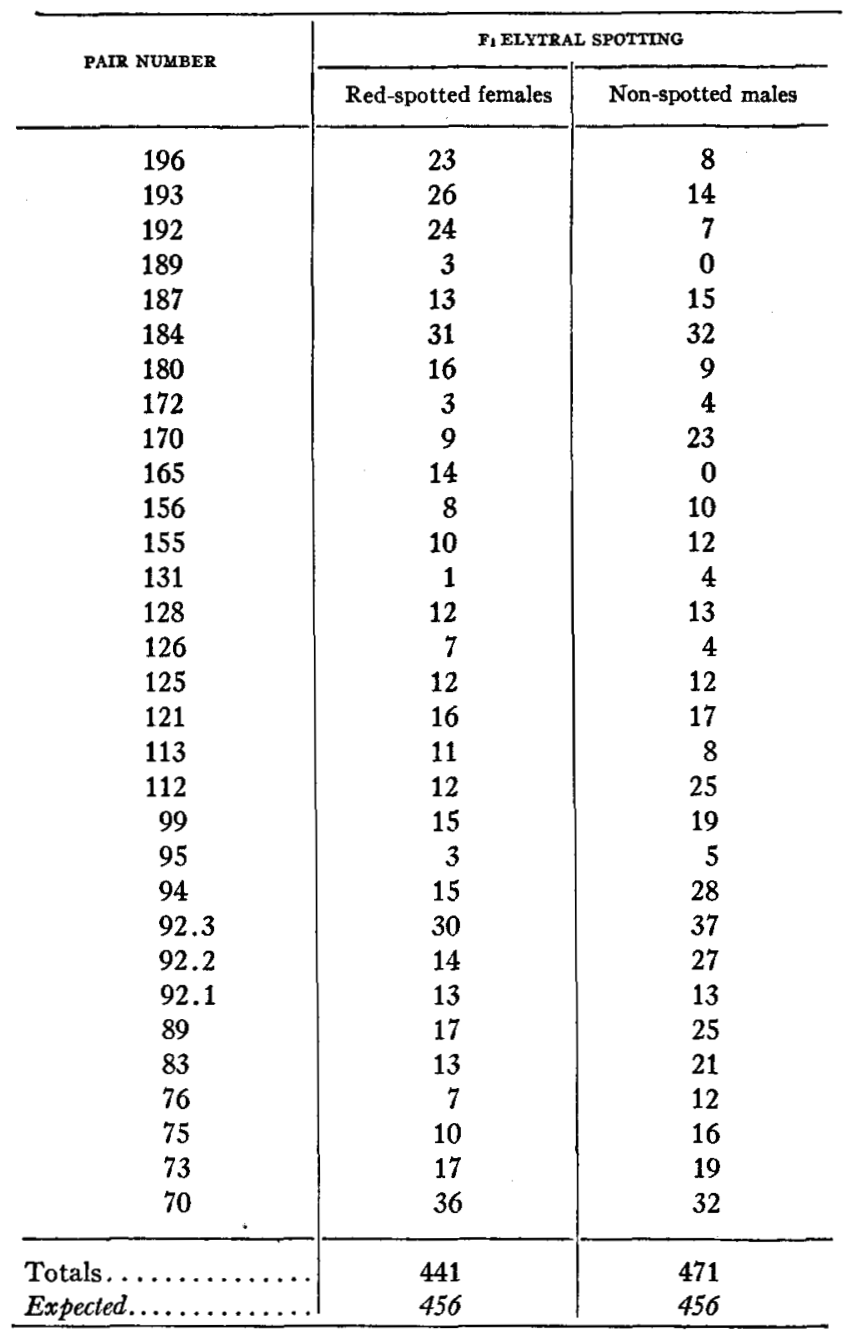

spotted females, 70 piebald females (34 were of the RB type and 36 of the BR kind), and 533 non-spotted males. This gives an actual ratio of $6: 1$, when the expected ratio should be $3: 1$ in the $F_{2}$ generation. The discrep- 
ancy is due to the fact that the piebald character is in many instances very minute. Therefore, during the earlier stages of the experiment, the spots frequently escaped observation and for that reason were not recorded. Hence, the data from table 1 is not added to those of the remaining tables.

\section{Piebald $B R$ females $(p p)$ mated with normal males $(P P)$}

Accurate breeding tests in which homozygous piebald $(p p)$ females were crossed with normal homozygous $(P P)$ males, were also conducted. The parents in thirty separate instances were piebald BR females $(p p)$, which were bred to non-spotted, normal males $(P P)$. The $\mathrm{F}_{1}$ offspring were normal, bilateral red-spotted females $(P p)$ and normal, non-spotted males, in approximately 1:1 sex-limited ratio, thus indicating that the piebald character is recessive. This set of tests is recorded in table 2 .

Table 3 is a continuation of the same test given in table 2 . In this experiment like-parents, piebald $\mathrm{BR}$ females $(p p)$, were mated with normal, non-spotted males $(P P)$. The data included tests for 31 separate $\mathrm{P}_{1}$ pairs. Their $\mathrm{F}_{1}$ progeny consisted of 441 bilateral red-spotted, heterozygous females $(P p)$, and 471 non-spotted, heterozygous males $(P p)$. The same sex-limited, $1: 1$, ratio is therefore evident. Hence, the conclusions from the data given in tables 2 and 3 prove that when a piebald $B R$ female is bred to a normal non-spotted male $(P P)$, all offspring are heterozygous $(P p)$ with piebald as a recessive.

\section{Piebald RB females ( $p p$ ) bred to normal males $(P P)$}

The information relative to such crosses is given in table 4. The $\mathrm{P}_{1}$ parents consisted of a piebald $\mathrm{RB}$ female $(p p)$ mated with a normal non-spotted male $(P P)$. The $\mathrm{F}_{1}$ progeny was heterozygous $(P p)$ and appeared normal. The female offspring from these parents appeared red-spotted, while the males were non-spotted. Forty separate $\mathrm{P}_{1}$ pairs gave 558 heterozygous normal red-spotted $(P p)$ females and 629 heterozygous normal non-spotted $(P P)$ males. Again a 1:1 sex-limited ratio is manifest. Therefore, the data from tables 2,3 and 4 prove that when any piebald $(p p)$ female, whether a $\mathrm{BR}$ or an $\mathrm{RB}$ one, enters the cross with a normal non-spotted $(P P)$ male, the $\mathrm{F}_{1}$ offspring is always normal and no piebald appears, thus indicating that the trait is recessive.

\section{The inheritance of a Pp female and a Pp male}

The offspring from heterozygous, $P p$, individuals is tabulated in table 5 . Each $F_{1}$ pair consisted of a red-spotted normal $(P p)$ female and a normal non-spotted $(P p)$ male. The thirty-two separate $F_{1}$ pairs totaled in the 
TABLE 4

$P_{1}$ : Piebald, $R B$ female $(p p) \times n$ non-spotted male $(P P)$ pure for red spots.

$F_{1}:$ Red-spotted females $(P p)$ and non-spotted males $(P p)$.

\begin{tabular}{|c|c|c|}
\hline \multirow[b]{2}{*}{ PATR NUMBEER } & \multicolumn{2}{|c|}{ F $_{1}$ ELYTRAL SPOTtING } \\
\hline & Red-spotted females & Non-spotted males \\
\hline 306 & 1 & 0 \\
\hline 296 & 3 & 3 \\
\hline 294 & 8 & 19 \\
\hline 281 & 9 & 5 \\
\hline 268 & 13 & 10 \\
\hline 257 & 22 & 11 \\
\hline 248 & 13 & 13 \\
\hline 239 & 9 & 12 \\
\hline 237 & 21 & 15 \\
\hline 232 & 16 & 16 \\
\hline 214 & 9 & 7 \\
\hline 211 & 28 & 24 \\
\hline 200 & 24 & 19 \\
\hline 199 & 25 & 38 \\
\hline 198 & 6 & 7 \\
\hline 197 & 19 & 28 \\
\hline 183 & 24 & 8 \\
\hline 181 & 3 & 5 \\
\hline 179 & 5 & 19 \\
\hline 177 & 18 & 18 \\
\hline 176 & 20 & 15 \\
\hline 175 & 27 & 15 \\
\hline 174 & 11 & 11 \\
\hline 168 & 14 & 10 \\
\hline 163 & 12 & 0 \\
\hline 157 & 17 & 15 \\
\hline 127 & 8 & 9 \\
\hline 123 & 12 & 12 \\
\hline 120 & 10 & 10 \\
\hline 119 & 9 & 11 \\
\hline 107 & 16 & 29 \\
\hline 103 & 21 & 29 \\
\hline 97 & 18 & 35 \\
\hline 96 & 11 & 18 \\
\hline 91 & 23 & 20 \\
\hline 90 & 10 & 12 \\
\hline 84 & 21 & 19 \\
\hline 80 & 26 & 41 \\
\hline 71 & 7 & 13 \\
\hline 67 & 10 & 16 \\
\hline $\begin{array}{l}\mathrm{s} . \ldots \ldots \\
\mathrm{cted} \ldots \ldots\end{array}$ & $\begin{array}{l}588 \\
608.5\end{array}$ & $\begin{array}{l}629 \\
608.5\end{array}$ \\
\hline
\end{tabular}


TABLE 5

$F_{1}:$ Red-spotted female $(P p) \times n o n$-spotted male $(P p)$.

\begin{tabular}{|c|c|c|c|c|}
\hline \multirow{4}{*}{$\begin{array}{c}\text { FI PAIR NUMBER } \\
.\end{array}$} & \multicolumn{4}{|c|}{ F: ELYTRAL SPOTTING } \\
\hline & \multicolumn{3}{|c|}{ Females } & \multirow{3}{*}{$\begin{array}{c}\text { Males } \\
\text { Non-spotted } \\
(P P, P p, p P, p p)\end{array}$} \\
\hline & \multirow{2}{*}{$\begin{array}{l}\text { Red-spotted } \\
(P P, P p, \not P)\end{array}$} & \multicolumn{2}{|c|}{ Piebald $(p p)$} & \\
\hline & & RB & $\mathrm{BR}$ & \\
\hline 309 & 13 & 2 & 3 & 19 \\
\hline 299 & 12 & 2 & 2 & 21 \\
\hline 297 & 15 & 6 & 0 & 23 \\
\hline 295 & 21 & 4 & 3 & 25 \\
\hline 292 & 11 & 2 & 2 & 12 \\
\hline 291 & 9 & 1 & 2 & 16 \\
\hline 290 & 5 & 1 & 1 & 15 \\
\hline 289 & 12 & 2 & 2 & 26 \\
\hline 284 & 2 & 0 & 1 & 3 \\
\hline 281.3 & 13 & 0 & 4 & 22 \\
\hline 281.2 & 17 & 3 & 4 & 20 \\
\hline 281.1 & 12 & 3 & 2 & 20 \\
\hline 261 & 12 & 2 & 2 & 10 \\
\hline 243 & 27 & 3 & 6 & 23 \\
\hline 240 & 20 & 7 & 2 & 34 \\
\hline 234 & 3 & 1 & 0 & 2 \\
\hline 227 & 17 & 4 & 4 & 23 \\
\hline 205 & 10 & 1 & 2 & 21 \\
\hline 195 & 20 & 4 & 1 & 14 \\
\hline 162 & 19 & 0 & 8 & 18 \\
\hline 159 & 7 & 1 & 2 & 11 \\
\hline 154 & 15 & 2 & 2 & 15 \\
\hline 153 & 2 & 1 & 0 & 13 \\
\hline 133 & 16 & 3 & 2 & 17 \\
\hline 130 & 18 & 3 & 3 & 24 \\
\hline 124 & 21 & 3 & 2 & 21 \\
\hline 117 & 5 & 1 & 2 & 5 \\
\hline 110 & 11 & 2 & 1 & 22 \\
\hline 104 & 8 & 2 & 0 & 10 \\
\hline 87 & 13 & 3 & 0 & 23 \\
\hline 86.1 & 4 & 2 & 0 & 9 \\
\hline 86 & 14 & 4 & 2 & 10 \\
\hline 85 & 17 & 2 & 3 & 17 \\
\hline 84.1 & 23 & 3 & 4 & 32 \\
\hline 82 & 11 & 2 & 1 & 17 \\
\hline 81.2 & 24 & 3 & 2 & 26 \\
\hline 81.1 & 21 & 7 & 2 & 24 \\
\hline 81 & 20 & 5 & 1 & 19 \\
\hline 80.1 & 21 & 4 & 2 & 29 \\
\hline 79.3 & 13 & 0 & 4 & 23 \\
\hline 79.1 & 16 & 4 & 0 & 16 \\
\hline 79 & 11 & 4 & 0 & 21 \\
\hline
\end{tabular}


TABLE 5 (continued)

\begin{tabular}{|c|c|c|c|c|}
\hline \multirow{4}{*}{$F_{1}$ PAIR NUMBER } & \multicolumn{4}{|c|}{ F, ELYTRAL SPOTTING } \\
\hline & \multicolumn{3}{|c|}{ Females } & \multirow{3}{*}{$\begin{array}{c}\text { Males } \\
\text { Non-spotted } \\
(P P, P p, p P, p p)\end{array}$} \\
\hline & \multirow{2}{*}{$\begin{array}{r}\text { Red spotted } \\
(P P, P p, \not P)\end{array}$} & \multicolumn{2}{|c|}{ Piebald $(p p)$} & \\
\hline & & $\mathrm{RB}$ & BR & \\
\hline 77 & 25 & 5 & 2 & 16 \\
\hline 75.3 & 14 & 3 & 2 & 21 \\
\hline 75.2 & 12 & 2 & 3 & 17 \\
\hline 74 & 16 & 3 & 2 & 21 \\
\hline 73.7 & 18 & 2 & 3 & 18 \\
\hline 72 & 3 & 1 & 0 & 5 \\
\hline 69 & 31 & 2 & 7 & 38 \\
\hline 68.2 & 6 & 2 & 1 & 9 \\
\hline 68 & 22 & 5 & 2 & 38 \\
\hline 65.1 & 30 & 6 & 2 & 46 \\
\hline 62.9 & 19 & 3 & 3 & 33 \\
\hline 62.7 & 40 & 7 & 4 & 51 \\
\hline 62.5 & 24 & 3 & 4 & 24 \\
\hline 62.4 & 18 & 3 & 3 & 25 \\
\hline 62.2 & 18 & 3 & 1 & 22 \\
\hline 62.1 & 13 & 4 & 1 & 25 \\
\hline Totals......... & 897 & 163 & 127 & 1192 \\
\hline Piebalds........ & 897 & & & 1192 \\
\hline Expected, $3: 1: 4$ & 900 & & & 1200 \\
\hline
\end{tabular}

$F_{2}$ generation, 411 red-spotted $(P P, P p, p P)$ females, 143 piebald $(p p)$ females ( 75 were of the RB type and 68 of the BR kind), and 547 nonspotted $(P P, P p, p P, p p)$ males. In table 6 , which is a continuation of table 5 , twenty-six separate $\mathrm{F}_{1}$ heterozygous pairs $(P p)$ produced in the $\mathrm{F}_{2}$ generation, 486 red-spotted $(P P, P p, p P)$ females, 147 piebald $(p p)$ females ( 88 were of the RB kind and 59 of the BR type), and 645 nonspotted $(P P, P p, p P, p p)$ males. The totals from table 5 are 897 redspotted females, 290 piebald females, of which 163 were RB and 127 BR, and 1192 non-spotted males. This result approximates a $3: 1: 4$ sex-limited ratio, or actually a 3:1 ratio, since all the males appeared alike. There were also a few more RB than BR piebald females enumerated in this experiment.

\section{Backcross test: $A$ PP female $\times$ a $P p$ male}

Homozygous normal bilateral red-spotted $(P P)$ females were mated to non-spotted heterozygous $\left(P_{p}\right)$ males. From $16 \mathrm{P}_{1}$ separate pairs, a total progeny of 291 normal red-spotted $(P P, P p)$ females, and 286 normal, 
non-spotted $(P P, P P)$ males was produced, which is a $1: 1$ sex-limited ratio. This shows the complete dominance of the normal character over the piebald. The data are given in table 6 .

TABLE 6

Backcross test.

$P_{1}: 1$ Red-spotted female $(P P) \times 1$ non-spotted male $\left(P_{p}\right)$.

\begin{tabular}{|c|c|c|}
\hline \multirow[b]{2}{*}{$P_{1}$ PAIR NUMBER } & \multicolumn{2}{|c|}{$F_{1}$ ELYTRAI SPOTtING } \\
\hline & Red-spotted females $(P P, P \boldsymbol{p})$ & Non-spotted males $(P P, P p$ \\
\hline 288 & 7 & 13 \\
\hline 286 & 11 & 15 \\
\hline 285 & 25 & 16 \\
\hline 84.2 & 12 & 16 \\
\hline 80.2 & 16 & 23 \\
\hline 77.8 & 30 & 30 \\
\hline 77.1 & 14 & 16 \\
\hline 75.1 & 39 & 21 \\
\hline 73.4 & 18 & 26 \\
\hline 73.3 & 16 & 17 \\
\hline 73.2 & 6 & 0 \\
\hline 71.3 & 12 & 10 \\
\hline 71.2 & 14 & 16 \\
\hline 71.1 & 28 & 30 \\
\hline 70.2 & 28 & 25 \\
\hline 70.1 & 15 & 12 \\
\hline Totals.......... & 291 & 286 \\
\hline Expected ....... & 288.5 & 288.5 \\
\hline
\end{tabular}

Backcross test: A Pp female $\times a$ PP male

This test, the complete data of which are given in table 7 , was the reciprocal of the previous one. The $P_{1}$ parents were heterozygous redspotted $(P p)$ females and homozygous non-spotted $(P P)$ males. Nineteen separate pairs mated produced 325 normal red-spotted $(P P, P p)$ females and 307 normal non-spotted $(P P, P p)$ males, which is a $1: 1$ sex-limited ratio. The results further confirm the previous tests, which showed that the normal trait is dominant to the recessive piebald.

\section{Backcross test: A BR piebald ( $p p)$ female $\times$ a $P p$ male}

Homozygous $(p p)$ BR piebald females bred to heterozygous nonspotted $(P p)$ males gave from the 12 separate pairs mated in the $\mathrm{F}_{1}$ generation, a total of 100 normal red-spotted $(P p)$ females, $37 \mathrm{RB}$ piebald $(p p)$ females, $51 \mathrm{BR}$ piebald $(p p)$ females, and 209 non-spotted $(P p, p p)$ males. By adding the two types of piebald females, 88 piebald $(p p)$ 
females are obtained. The observed ratio is $100: 88: 209$ which approximates a 1:1:2 sex-limited ratio. This experiment proves that the characters, normal and piebald, segregate as a $1: 1$ ratio, if only the two types of piebald females are added. It illustrates that the pied trait is a recessive to the normal. However, the RB piebald females in this test did not breed true for the RB type but again produced two kinds, the $R B$ and $B R$, in about equal numbers. No male manifested the piebald character. The results are given in table 8 .

TABLE 7

Reciprocal backcross test.

$P_{1}: 1$ red-spotted $(P p)$ female $\times 1$ non-spotted $(P P)$ male.

\begin{tabular}{c|c|c}
\hline & \multicolumn{2}{|c}{$\mathbb{P}_{i}$ ELXTRAL SPotTing } \\
\cline { 2 - 3 } $\mathbf{P}_{1}$ PaIR NUMBER & $\begin{array}{c}\text { Females } \\
\text { Red-spotted }(P P, P p)\end{array}$ & $\begin{array}{c}\text { Males } \\
\text { Non-spotted }(P P, P p)\end{array}$ \\
\hline 69.1 & 7 & 5 \\
62.6 & 1 & 2 \\
62.3 & 33 & 30 \\
61.1 & 20 & 15 \\
61.4 & 0 & 2 \\
61.5 & 27 & 21 \\
61.6 & 18 & 22 \\
61.9 & 22 & 29 \\
61.10 & 15 & 22 \\
61.11 & 0 & 3 \\
61.12 & 8 & 7 \\
61.13 & 5 & 12 \\
61.14 & 3 & 9 \\
61.15 & 12 & 4 \\
61.16 & 13 & 2 \\
61.52 & 26 & 17 \\
61.51 & 24 & 20 \\
61.42 & 22 & 24 \\
61.43 & 69 & 61 \\
\hline
\end{tabular}

Backcross test: An RB piebald ( $p p$ ) female $\times$ a Pp male

This test is the same as the previous one with the exception that an $R B$ piebald female was used instead of a BR female. The experiment is given in table 9. The parents were homozygous RB ( $p p)$ females and heterozygous, non-spotted $(P P)$ males. Twenty separate pairs produced 176 normal red-spotted $(P p)$ females, $105 \mathrm{RB}$ piebald $(p p)$ females, $59 \mathrm{BR}$ piebald $(p p)$ females, and 356 non-spotted $(P p, p p)$ males. By adding 
together the two kinds of piebald $(p p)$ females, 164 were obtained. The actual ratio was 176:164:356, approximating a 1:1:2 sex-limited ratio. This test proves that piebald is a recessive homozygous trait when the two types, dextral and sinistral, are added. Lastly, the two different piebald patterns, RB and BR, did not breed true for each different kind, but each produced both types in about equal numbers.

TABLE 8

Backcross test.

$P_{1}$ : A piebald BR female $(p p) \times a$ non-spotted male $(P p)$.

\begin{tabular}{|c|c|c|c|c|}
\hline \multirow{4}{*}{ PI PAIR NUMBER } & \multicolumn{4}{|c|}{$F_{3}$ ELYTRAL SPOTTING } \\
\hline & \multicolumn{3}{|c|}{ Females } & \multirow{3}{*}{$\begin{array}{c}\text { Males } \\
\text { Non-spotted } \\
(P p, p p)\end{array}$} \\
\hline & \multirow[b]{2}{*}{$\begin{array}{l}\text { Red-spotted } \\
\quad(P p)\end{array}$} & \multicolumn{2}{|c|}{ Piebald $(p p)$} & \\
\hline & & $\mathrm{RB}$ & $\mathrm{BR}$ & \\
\hline 282.2 & 2 & 0 & 2 & 3 \\
\hline 247 & 8 & 7 & 0 & 16 \\
\hline 246 & 9 & 0 & 5 & 15 \\
\hline 244 & 3 & 0 & 3 & 13 \\
\hline 216 & 17 & 0 & 11 & 27 \\
\hline 210 & 16 & 0 & 15 & 22 \\
\hline 186 & 8 & 11 & 0 & 19 \\
\hline 79.2 & 15 & 4 & 7 & 15 \\
\hline 78 & 2 & 1 & 2 & 9 \\
\hline 79.9 & 6 & 7 & 1 & 34 \\
\hline 77.2 & 5 & 4 & 0 & 13 \\
\hline 66.1 & 9 & 3 & 5 & 23 \\
\hline \multirow{2}{*}{ Totals. } & & 37 & 51 & \\
\hline & 100 & \multicolumn{2}{|c|}{88} & 209 \\
\hline Expected, $1: 1: 2$ & 99 & \multicolumn{2}{|c|}{99} & 198 \\
\hline
\end{tabular}

A $p p$ female $\times a p p$ male

The result of this test is given in table 10. Each pair mated consisted of a piebald $(p p) \mathrm{RB}$ female and a non-spotted $(p p)$ male, both of which were homozygous for the piebald factor. Twelve separate pairs gave a total of $109 \mathrm{RB}$ piebald $(p p)$ females, $100 \mathrm{BR}$ piebald $(p p)$ females and 213 non-spotted $(p p)$ males. By adding the two types of piebald $(p p)$ females, a total of 209 piebald females is obtained, which approximates a 1:1 sex-limited ratio. The ratio is a sex-limited one because the piebald trait is not visible in the male. It further demonstrates that this mutation bred pure for piebald, when the two types of piebald females were added together. Furthermore, the RB piebald females were about equal, though 
the BR pattern was slightly in excess. Lastly, this experiment proved that the homozygous RB piebald female mated with a non-spotted male, homozygous for piebald, did not breed true for the RB unilateral pattern, but always produced two types, the $R B$ and $B R$, in about equal numbers.

TABLE 9

Backcross test.

$P_{1}$ : A piebald $R B$ female $(p p) \times a$ non-spotted male $(P p)$.

\begin{tabular}{|c|c|c|c|c|}
\hline \multirow{4}{*}{ Yi PAIR NUMBER } & \multicolumn{4}{|c|}{ F1 $_{1}$ LYTRAL SPOTTING } \\
\hline & \multicolumn{3}{|c|}{ Females } & \multirow{3}{*}{$\begin{array}{c}\text { Males } \\
\text { Non-spotted } \\
(P p, p p)\end{array}$} \\
\hline & \multirow[b]{2}{*}{$\begin{array}{l}\text { Red-spotted } \\
\qquad(P p)\end{array}$} & \multicolumn{2}{|c|}{ Fiebald $(p p)$} & \\
\hline & & $\mathbf{R B}$ & BR & \\
\hline 235 & 3 & 4 & $\mathbf{0}$ & 8 \\
\hline 228 & 9 & 5 & 5 & 27 \\
\hline 226 & 5 & 3 & 9 & 2 \\
\hline 225 & 19 & 8 & 2 & 26 \\
\hline 223 & 4 & 5 & $\mathbf{0}$ & 13 \\
\hline 282 & 8 & 0 & 6 & 16 \\
\hline 208 & 12 & 10 & 3 & 27 \\
\hline 205 & 9 & 7 & 4 & 24 \\
\hline 204 & 13 & 10 & 0 & 14 \\
\hline 202 & 24 & 16 & 5 & 36 \\
\hline 201 & 11 & 10 & 2 & 22 \\
\hline 188 & 6 & 6 & 0 & 25 \\
\hline 185 & 1 & 1 & 0 & 7 \\
\hline 173 & 5 & 3 & 1 & 7 \\
\hline 169 & 5 & 4 & 0 & 15 \\
\hline 160 & 12 & 2 & 10 & 23 \\
\hline 118 & 4 & $\mathbf{0}$ & 3 & 5 \\
\hline 777 & 6 & 0 & 9 & 14 \\
\hline 773 & 11 & 5 & 4 & 18 \\
\hline 628 & 9 & 6 & 2 & 27 \\
\hline \multirow{2}{*}{ Totals..... } & & 105 & 59 & \\
\hline & 176 & \multicolumn{2}{|c|}{164} & 356 \\
\hline Expecled, $1: 1: 2$ & 174 & & & 348 \\
\hline
\end{tabular}

$A$ summary of the $R B$ and $B R$ piebald females

A summary of the two kinds of piebald females, the RB and the BR types, is given in table 11. These totals show that for the piebald females, 448 manifested the RB spotting and 373 the BR pattern; that is, those females having the red spots on the left elytrum and black ones on the right were more frequent than those having black spots on the left elytrum 
and red spots on the right. The numbers for all tests were about equal.

The conclusions from this set of tests are, first, that piebald is a sexlimited recessive, visible only in the females, and second, that the character is always seen on either the left or right elytrum, never on both at the same time.

TABLE 10

$P_{1}: A$ piebald $R$ B female $(p p) \times a$ non-spotted male $(p p)$.

\begin{tabular}{|c|c|c|c|}
\hline \multirow{3}{*}{ F1 PAIR NUMBBER } & \multicolumn{3}{|c|}{ Fy ELYTRAL SPOTIING } \\
\hline & \multicolumn{2}{|c|}{$\begin{array}{c}\text { Females } \\
\text { Piebald }(p p)\end{array}$} & \multirow{2}{*}{$\begin{array}{c}\text { Males } \\
\text { Non-spotted } \\
(\phi p)\end{array}$} \\
\hline & R B & B R & \\
\hline 304 & 0 & 1 & 3 \\
\hline 222 & 15 & 15 & 18 \\
\hline 221 & 1 & 0 & 12 \\
\hline 213 & 5 & 14 & 14 \\
\hline 212 & 24 & 0 & 25 \\
\hline 209 & 12 & 5 & 24 \\
\hline 190 & 7 & 11 & 19 \\
\hline 182 & 2 & 0 & 2 \\
\hline 129 & 11 & 6 & 23 \\
\hline 116 & 9 & 17 & 29 \\
\hline 111 & 12 & 13 & 20 \\
\hline 109 & 11 & 18 & 24 \\
\hline \multirow{2}{*}{ Totals.. } & 109 & \multirow[t]{3}{*}{100} & \\
\hline & 209 & & 213 \\
\hline Expected $\ldots \ldots \ldots$ & 211 & & 211 \\
\hline
\end{tabular}

TABLE 11

A summary of the piebald females ( $p p)$.

\begin{tabular}{c|c|c}
\hline \multirow{2}{*}{ TOTALS FROM TABIE NUMBER } & \multicolumn{2}{|c|}{ PIEBAID FEMALES } \\
\cline { 2 - 3 } & $\mathrm{RB}$ & BR \\
\hline 1 & 34 & 36 \\
5 & 75 & 68 \\
6 & 88 & 59 \\
9 & 37 & 51 \\
10 & 105 & 59 \\
11 & 109 & 100 \\
\hline & 448 & 373 \\
\hline
\end{tabular}




\section{DISCUSSION}

Since the two bilateral pigmented areas of Bruchus have definite boundaries, appearing always in the same position on the elytra of the females, they form a pattern resembling, somewhat, the many piebald traits in animals. Aside from the sex-differences, they suggest Allen's "centers of pigmentation" (ALLEN 1904), especially since there are other pigmented areas located elsewhere on this weevil, which are not sexlimited. Careful examination of the several available species of Bruchidae show that the sexes are not easily distinguished, except in $B$. quadrimaculatus, though each species manifests a design peculiar to its kind.

In Bruchus, symmetry is externally visible in the duplication of spots, patterns, colors, elytra, antennae, legs, etc., while asymmetry is rarely manifested externally. Inherited asymmetry is illustrated by this piebald mutation, originating from purely symmetrical insects.

In order to study the inheritance of this trait successfully, it was necessary to contrast the normal bilaterality with the abnormal asymmetry. This was accomplished by injuring the pupae on one side, thus producing asymmetrical elytra colors in the adult female. Such abnormalities were not inherited, though some were similar to the elytral spotcolor mosaics, a list of which has been published (BREITENBECHER 1922). These were also non-inherited, but were interpreted, at that time, as somatic mutations. The most frequent mosaic type, red spots on one elytrum and black spots on the other, resembles this piebald mutation, except for its heritability.

The actual cause of sex-limited differences in insects has not been conclusively demonstrated. One of the theories advanced by GoLDSCHMIDT and FisCHER (1922) in explanation of sex-controlled characters in Lepidoptera seems to apply to these traits in Bruchus, since the male shows himself a fraction of a day earlier than the female. However, only twenty percent of the mutations in this weevil are sex-limited, although in every mutation discovered the males issued at the same time, whether sex-limited or not; hence, some other explanation should account for the remaining eighty percent, unless it is assumed that such characters develop more rapidly. According to Brooks (1922) the $\mathrm{Y}$ chromosome is absent in Bruchus; therefore, BRIDGES's (1922) interpretation that both sexual and sex-limited characters depend upon "modifiers" within the X chromosome of Drosophila, upon further investigation, may be found to be equally applicable to Bruchus.

The results of selection are negative. Since the males for both types of pied females appear alike, it is impossible to distinguish them. It is not 
unreasonable to suppose that in this experiment, comprising a great number of matings, an RB female will have been mated with an RB male at least half the time, and that their offspring should breed true for this type; but such pairs always produced, on the average. one dextral female, one sinistral female and two normal males, regardless of the character of the parents which entered the test.

The piebald trait for Bruchus is an instance of bilateral asymmetry. The bilaterality is shown by the arrangement of the two spots on each elytrum. The asymmetry is manifested by the color differences of these spots. If this pied character is considered as unilateral, the black spots representing this condition, then the red spots might be the result of normal genes. Or, if the bilateral red spots should be the trait, then a unilateral inhibitor might make the color difference. There seems to be some delicate adjusting mechanism which shifts the asymmetrical spotting right and left according to chance, since equal numbers of dextrals and sinistrals is produced.

\section{CONCLUSTONS}

1. The sexes in homozygous piebald cultures are dissimilar in appearance. The female has two black spots on one elytrum and two red spots on the other, or vice versa, equal numbers dextral and sinistral. The male has no elytra spots and is without dextral or sinistral differences.

2. This trait is sex-limited although it is transmitted equally by both sexes.

3. The piebald mutation is a recessive, the typical recessive frequency being obtained by adding together the dextral and sinistral females.

4. This character is called piebald, since it varies in the amount of spotting and size of spots.

5. Symmetry is normally manifested in this insect by the duplications of spots, patterns, colors, antennae, elytra, legs, etc., while asymmetry is rarely seen externally.

6. This piebald-asymmetry is inherited, while asymmetries discovered for mosaics and from experimental injuries were not.

7. This trait has a normal bilaterality and symmetry in the pupal state, its asymmetry not being visible until the insect becomes adult.

8. Unilateral characters in animals are usually limited to one body side. However, this type of unilaterality is not found in this piebald trait, since dextral females always produce both dextral and sinistral insects in equal numbers.

9. Probably some delicately adjusting mechanism shifts this asymmetry right or left according to chance. 
10. Lastly, the piebald trait for Bruchus is an instance of inherited bilateral asymmetry.

\section{LITERATURE CITED}

Allen, G. M., 1904 The heredity of coat colors in mice. Proc. Amer. Acad. Arts and Sci. 40: $61-163$.

Breitenbecher, J. K., 1921 The genetic evidence of a multiple (triple) allelomorph system in Bruchus and its relation to sex-limited inheritance. Genetics 6: 55-90.

1922 Somatic mutations and elytral mosaics in Bruchus. Biol. Bull. 43: 10-23.

1923 A red-spotted sex-limited mutation in Bruchus. Amer. Nat. 57: 59-65.

BRIDGES, C. B., 1922 The origin of variations in sexual and sex-limited characters. Amer. Nat. 56: $51-63$.

Brooks, Frank C., 1922 A preliminary note on the chromosome number in the spermatocytes of Bruchus. Proc. Oklahoma Acad. Sci. 2: 49-52.

GoldschmidT, R., and Fischer, E., 1922 Argynnis paphia-valesina, ein Fall geschlechtskontrollierter Vererbung bei Schmetterlingen. Genetica 4: 247-278. 